\title{
вмJ Global Health Compact for care: how the Affordable Care Act marketplaces fell short for a vulnerable population in Hawaii
}

\author{
Joshua S Ng Kamstra, ${ }^{1,2}$ Teresa Molina,, ${ }^{3,4}$ Timothy Halliday ${ }^{3,4}$
}

To cite: Ng Kamstra JS, Molina T, Halliday T. Compact for care: how the Affordable Care Act marketplaces fell short for a vulnerable population in Hawaii. BMJ Global Health 2021;6:e007701. doi:10.1136/ bmjgh-2021-007701

Handling editor Seye Abimbola

Received 13 October 2021 Accepted 8 November 2021
Check for updates

(C) Author(s) (or their employer(s)) 2021. Re-use permitted under CC BY-NC. No commercial re-use. See rights and permissions. Published by BMJ.

${ }^{1}$ The Queen's Health Systems, Honolulu, Hawaii, USA

${ }^{2}$ Department of Surgery, University of Hawai'i at Manoa John A Burns School of Medicine, Honolulu, Hawaii, USA ${ }^{3}$ Department of Economics, University of Hawai'i at Manoa, Honolulu, Hawaii, USA ${ }^{4}$ IZA Institute of Labor Economics, Bonn, NordrheinWestfalen, Germany

Correspondence to Dr Joshua S Ng Kamstra; josh.ngkamstra@gmail.com

\section{ABSTRACT}

The Patient Protection and Affordable Care Act (ACA) was passed in 2010 to expand access to health insurance in the USA and promote innovation in health care delivery. While the law significantly reduced the proportion of uninsured, the market-based protection it provides for poor and vulnerable US residents is an imperfect substitute for government programs such as Medicaid. In 2015, residents of Hawaii from three Compact of Free Association nations (the Federated States of Micronesia, Palau and Marshall Islands) lost their eligibility for the state's Medicaid program and were instructed to enrol in coverage via the ACA marketplace. This transition resulted in worsened access to health care and ultimately increased mortality in this group. We explain these changes via four mechanisms: difficulty communicating the policy change to affected individuals, administrative barriers to coverage under the ACA, increased out of pocket health care costs and short enrolment windows. To achieve universal health coverage in the USA, these challenges must be addressed by policy-makers.

\section{INTRODUCTION}

Worldwide, one in ten people experiences financial catastrophe due to a medical emergency every year. ${ }^{1}$ Such financial risks act as a deterrent to seeking care among the uninsured, leading to worsened health outcomes. ${ }^{23}$ In the USA, the high costs of care coupled with a large proportion of uninsured individuals contributes to substantial annual risks of catastrophic health expenditures. ${ }^{4}$ Low-income individuals, migrants and those with limited English proficiency (LEP) are at particular risk. ${ }^{56}$

The Patient Protection and Affordable Care Act (ACA) expanded insurance coverage, in part, by providing a market-based insurance option to individuals who were otherwise uninsured by Medicaid, Medicare, the Children's Health Insurance Program or employer-sponsored coverage. ${ }^{7}$ The ACA mandated individual coverage with financial penalties for those who remained unenrolled, provided subsidies to offset the cost of

\section{Summary box}

- Residents of the US state of Hawaii from the Federated States of Micronesia, Marshall Islands and Palau lost health insurance provided by the state Medicaid program in 2015, and were instructed to instead apply for coverage via the Affordable Care Act (ACA) marketplace.

- This policy change resulted in a dramatic worsening of health outcomes, including all-cause mortality in this population.

- The ACA marketplaces are an imperfect substitute for Medicaid for vulnerable populations.

- Complex communication challenges around eligibility, the administrative burden of enrolment, new out-of-pocket costs for care and a limited enrolment window explain why the marketplace performed worse than Medicaid for this population.

purchasing coverage for low-income individuals, provided incentives for states to expand Medicaid coverage and guaranteed coverage for those with pre-existing conditions. ${ }^{8}$ This legislation was effective in reducing the number of uninsured individuals and contributed to improved health outcomes in those who were newly covered via the ACA marketplaces. ${ }^{9}$ Despite this progress, important coverage gaps remain in the USA.

Recent events have demonstrated that the ACA marketplaces are not always effective replacements for public insurance programmes such as Medicaid. For example, in 2015, the state of Hawaii rescinded access to its state-financed Medicaid programme for most migrants from three Pacific Island nations, which are signatories of separate Compacts of Free Association (COFA) with the USA: the Federated States of Micronesia, the Republic of the Marshall Islands and the Republic of Palau. To compensate for the resulting coverage gap, citizens of these nations, also known as COFA migrants, were instructed to enrol in subsidised privately purchased insurance newly 
available on the exchanges set up by the ACA. This transition worsened insurance coverage, healthcare use and mortality ${ }^{10}{ }^{11}$ demonstrating that the structure of health insurance products influences their uptake, use and effectiveness in vulnerable populations.

The experience of COFA migrants demonstrated that the ACA marketplaces are an imperfect substitute for Medicaid. We point to four mechanisms that may explain why marketplace-based insurance performed worse than Medicaid for this population: complex communication challenges around eligibility, the administrative burden of enrolment, new out-of-pocket costs for care and a limited enrolment window. Understanding and addressing these mechanisms affords policy-makers broad opportunities for more effective legislation in the pursuit of universal health coverage in the USA.

\section{HISTORY OF THE COMPACTS AND ASSOCIATED HEALTH POLICY}

In 1947, the United Nations granted the USA a trusteeship over several Pacific Island nations. ${ }^{12}$ The trusteeship granted the right to use lands for military purposes including the establishment of bases and fortifications in exchange for the obligation to promote independent governance, economic and educational advancement, and social goods including health protection. In the ensuing decades, the USA availed itself of its military rights under the trusteeship and undertook extensive testing of nuclear weapons, most notably in the Marshall Islands. ${ }^{13}$ As the trusteeship ended, a Compact of Free Association was formalised between the USA and each of the Federated States of Micronesia, the Republic of the Marshall Islands and the Republic of Palau. ${ }^{14}$ The Compacts allow for continued US military presence, include provisions that allowed COFA residents to reside and work in the USA without a visa, and appropriated funds for improving healthcare and education in the island nations.

Over 56000 COFA migrants now live in the USA. ${ }^{15}$ Most are employed, and rates of participation in the US military are high. ${ }^{1617}$ Transpacific migration continues to increase, as Pacific Islanders face the impact of climate change and seek opportunities in the USA. ${ }^{18}$ In table 1, we use the 2015-2019 American Community Survey to provide basic demographic and economic statistics on COFA migrants in the state of Hawaii. ${ }^{19}{ }^{20}$ Compared with the rest of the state, COFA migrants are much younger (mean age 25 vs 40 years). Mean income of COFA migrants is also substantially lower, and this is not only because of their younger average age: even within age categories, COFA migrants earn much less. For example, average annual income for COFA migrants aged 20-34 is $\$ 17800$, compared with $\$ 31700$ for the rest of the population. COFA migrants aged between 35 and 49 earn $\$ 24$ 400 , less than half of the average among the rest of the population $(\$ 55000)$.

In 1996, the US Personal Responsibility and Work Opportunity Act removed federal Medicaid funding for COFA residents by what is largely believed to be a drafting error. $^{2122}$ The state of Hawaii continued to fund healthcare for COFA migrants via its Medicaid managed care programme, Med-QUEST (Quality care, Universal access, Efficient utilization, Stabilizing costs, and Transforming care experiences).

\section{BASIC HEALTH HAWAII, RACISM AND DISCRIMINATION}

Following the global financial crisis of 2007-2008, the Governor of Hawaii reversed this decision. COFA residents were instead to be enrolled in a plan that restricted individual health expenditures called Basic Health Hawaii. This plan, implemented in July 2010, severely restricted access to care, limiting hospital days, outpatient visits, and prescription drugs, and cut patients off from chemotherapy and dialysis. The government's decision to target their healthcare as a cost-saving measure was apparent to COFA residents, and they felt that this policy gave the general population 'permission to lash out on [them]'. ${ }^{23}$ In addition to losing access to care, harms accrued due to the experience of racism in healthcare and daily life, negative media coverage, and racist rhetoric from government representatives. ${ }^{23-25}$

The loss of Med-QUEST coverage was challenged by a lawsuit brought on behalf of COFA migrants. ${ }^{26}$ An injunction in December 2010 stayed this decision, ${ }^{27}$ reinstating coverage until 2014, when a judicial panel decided in favour of the state. ${ }^{628}$ COFA residents lost coverage in March 2015, by which time the Affordable Care Act had passed. A 60-day special enrolment period (SEP) was then offered for these individuals to enrol in coverage via the ACA marketplace. ${ }^{21}$

Table 1 Demographics of Hawaii Compacts of Free Association (COFA) population

\begin{tabular}{|c|c|c|c|c|c|c|c|c|c|c|}
\hline & \multicolumn{2}{|l|}{ All ages } & \multicolumn{2}{|l|}{ Under 20} & \multicolumn{2}{|l|}{$20-34$} & \multicolumn{2}{|l|}{$35-49$} & \multicolumn{2}{|l|}{ Over 50} \\
\hline & COFA & Other & COFA & Other & COFA & Other & COFA & Other & COFA & Other \\
\hline Age & $25.3(18.5)$ & 40.1 (23.6) & $8.63(5.25)$ & $9.23(5.70)$ & 27.7 (3.89) & $27.1(4.26)$ & 40.7 (4.39) & $41.8(4.35)$ & $60.5(10.1)$ & $65.7(11.0)$ \\
\hline $\begin{array}{l}\text { Income (in } \\
\text { thousands) }\end{array}$ & $17.4(23.8)$ & $43.9(54.9)$ & $2.10(6.80)$ & $3.62(8.85)$ & $17.8(21.4)$ & $31.7(31.5)$ & 24.4 (26.9) & $55.0(58.2)$ & $14.0(24.7)$ & $51.0(62.8)$ \\
\hline $\mathrm{N}$ & 898 & 70502 & 413 & 15240 & 201 & 12976 & 170 & 12604 & 114 & 29682 \\
\hline
\end{tabular}

Source: Authors' calculations from the 2015 to 2019 American Community Surveys. COFA migrants identified using the Census Bureau definition. Income is reported in thousands of 2019 US $\$$ and is only available for those aged 15 and older. Table reports means and standard deviations in brackets. 
IMPACT ON HEALTHCARE USE AND HEALTH OUTCOMES AFTER 2015

If insurance via the marketplace was a perfect substitute for Medicaid, no change in healthcare use in this population would occur. A recent analysis assessed hospitalisations and emergency department (ED) visits between January 2014 and December 2015. ${ }^{10}$ Among adult Micronesians (age 18-64), Medicaid-funded hospitalisations and ED visits declined by $31 \%$ and $19 \%$, respectively. There was an increase in visits funded via private insurance that did not compensate for this decline. Importantly, there was a marked increase in uninsured ED visits.

Additionally, in a separate analysis of mortality among Micronesian, Japanese and white residents of Hawaii from 2012 to 2018, Micronesians experienced a dramatic relative increase in mortality beginning in 2016. ${ }^{11}$ By 2018 , the relative change in mortality was $43 \%$ higher for Micronesians than for white residents. While it is difficult to infer causality from observational data, the quasiexperimental nature of these studies using difference-indifference methods and incorporating two comparison populations (Japanese and white residents of Hawaii) suggests that the policy change for COFA residents in 2015 both decreased healthcare use and increased mortality. We will now explore potential mechanisms that explain these findings and contextualise them within the existing literature.

\section{MECHANISM 1: COMPLEX COMMUNICATION CHALLENGES}

To move thousands of people off a state-funded plan to private insurance without a catastrophic loss of health coverage, the state had to communicate the nature of the policy change, who it affected, and the steps required by individuals to enrol via the marketplace. Compounding this challenge was the high proportion of COFA households $(52.3 \%)$ reporting challenges with accessing services due to LEP. ${ }^{29}$ Other US contexts have demonstrated that those with LEP are much less likely to be insured than other populations, both because of related socioeconomic barriers and the direct impact of difficulty understanding printed materials and communication with insurance providers. ${ }^{530}$

In this context, efforts were made to assist individuals with signing up for marketplace plans, including community-based outreach workers called Kōkua, meaning 'help' in the Hawaiian language ${ }^{31}$ Further, an autoenrolment strategy was established, so that individuals who had not chosen one of the two market-dominant health plans, Kaiser Permanente or Hawaii Medical Services Association (HMSA), were divided between the two plans. Unfortunately, several months after this process, the Hawaii state marketplace was closed after problems with its rollout, and therefore individuals needed to enrol again via the Federal marketplace. ${ }^{32}$

That communication failures contributed to the decrease in healthcare utilisation is empirically demonstrable. The policy change affected adult COFA migrants who were not aged, blind or disabled (ABD). Children, pregnant women and ABD individuals remained eligible for Med-QUEST, and so healthcare use and outcomes should have been unchanged in these groups. However, inpatient admissions declined for infants and children, while ED visits increased, suggesting decreased utilisation of ambulatory care. ${ }^{10}$ This may be indicative of a reverse woodworking effect, whereby communications about Medicaid expiration to one group inadvertently discouraged healthcare use in another group whose eligibility remained unaffected.

Understanding the diversity of health literacy is critical in communications around enrolment. A qualitative study of Marshallese migrants revealed that some had a nuanced understanding of the ACA and the steps required to enrol, while others remained uncertain of their eligibility and reported receiving conflicting information from officials. ${ }^{16}$ To improve access to necessary information and prevent discrimination against those with LEP in accordance with Section 1557 of the ACA, a 2016 rule mandated that no-cost language services be provided to those seeking and using health insurance. In 2020, the Republican administration reversed this interpretation, removing the requirement for individual language assistance and the obligation to notify individuals of the availability of this assistance. ${ }^{33}$ Reinstating language access is an urgent priority in order to reduce the proportion of uninsured among populations with LEP.

\section{MECHANISM 2: ADMINISTRATIVE BURDEN}

Applying for insurance takes time and effort, with significant demands for documentation and follow-up communication. The heavier these burdens, the fewer people will apply. This has been demonstrated in the American context with respect to applications for Medicaid. ${ }^{34} 35$ In addition to the learning cost where individuals must explore and understand the options available to them as previously discussed, Moynihan, Herd and Harvey describe two other administrative barriers to acquiring health insurance. ${ }^{36}$ First, the psychological cost is paid by enduring stigma that may be encountered during the application process and the stress that the process may impart. In 2015, the psychological costs to COFA migrants in Hawaii were large. Migrants were being asked to reapply for private insurance after the state government had just defunded their healthcare. In one study, Marshallese migrants expressed frustration and anger that after decades of paying taxes and contributing to the economy, they were ineligible for Medicaid. ${ }^{16}$ Many gave up trying to apply for health insurance entirely. ${ }^{23}$ Second, the compliance cost demands that individuals prove eligibility for the programme via proof of identity and residence, income level and other necessary criteria. Despite the fact that COFA migrants are free to live in the USA without documentation as per the Compact, enrolling in the exchanges required government-issued 
identification and an I-94 status document; the latter could cost hundreds of dollars to replace if no digital or paper copy was available. ${ }^{31}$ Furthermore, even after providing all necessary documentation and following up with administrators, it could take months before eligibility was determined. ${ }^{1637}$

Numerous strategies to overcome these burdens for other vulnerable populations have been studied. While success has been mixed, common themes include the need for deeper community engagement, the availability of trained assisters with knowledge of how to address population-specific barriers (as the Kōkua outreach workers were intended), and a need to minimise bureaucratic requirements. ${ }^{38-41}$

Some administrative burdens are unavoidable to ensure that an individual is indeed eligible and that there are no better alternative insurance options. However, adverse selection, which could occur if individuals only seek coverage during illness or prior to anticipated health expenditures, might be exacerbated by higher burdens. If less healthy individuals are more tolerant of administrative hurdles, this would result in higher average health expenditures among those who persist through enrolment. ${ }^{42}$ Streamlining the application process might therefore provide benefit to both the insurer and the insured. Moreover, a safety net programme whose administrative barriers excludes eligible people from healthcare has failed those individuals, making the minimisation of such barriers a moral choice.

\section{MECHANISM 3: OUT OF POCKET EXPENDITURES}

Under Med-QUEST, COFA residents faced no direct patient-borne costs of care. After a move to the marketplace, individuals could anticipate the costs of premiums, deductibles and co-payments associated with purchasing insurance and accessing care. The cost of premiums was high compared with income; the monthly cost of the standard 'Second Lowest Cost Silver Plan' for an individual could be well over US $\$ 300,{ }^{43}$ against an average annual income of US\$17400 (see table 1).

COFA residents were ineligible for federal premium subsidies. The state government committed to assisting with the cost of premiums for those individuals who chose a Silver-tier plan, earned less than $100 \%$ of the FPL, and who were able to verify income for the previous year. Individuals meeting these criteria were flagged by insurers, and the cost of premiums was billed to the state government. ${ }^{31}$ Failing to meet any of these criteria would be sufficient to render an individual ineligible, and so uptake of the premium assistance programme was less than expected. ${ }^{31}$

Even if an individual received premium assistance, the out-of-pocket costs could impact realised access to healthcare. In the COFA population, individuals were arbitrarily split between Kaiser and HMSA, with the former waiving these charges and the latter applying them. ${ }^{10}$ Although in this context, it did not appear as if these user charges directly decreased healthcare utilisation, this phenomenon is well established in the literature. ${ }^{244-46}$

Cost-sharing is intended to decrease costs borne by the insurer and improve the efficiency of healthcare. However, by introducing financial barriers to accessing care, it may paradoxically worsen efficiency by decreasing the use of primary care. ${ }^{47}$ Accessing primary health services may not be cost-saving, but can be highly costeffective. ${ }^{48}$ Reducing cost sharing might increase the use of primary and secondary preventive healthcare, which has been shown to improve health outcomes, although often at higher cost. This is therefore an important policy lever to consider when insuring vulnerable populations.

\section{MECHANISM 4: LIMITED ENROLMENT WINDOW}

Open enrolment via the marketplace takes place on a limited annual basis. The initial open enrolment period was 6 months. ${ }^{49}$ Thereafter, individuals had a designated 3-month window each year to apply for coverage, until this was reduced federally to 6 weeks in $2017 .^{50}$ The rationale for limited windows is to prevent adverse selection. However, this comes at the cost of imposing a temporal barrier to coverage for those who miss the annual window to apply. SEPs are made available to individuals with a change in status (eg, a loss of workplace insurance). COFA residents in Hawaii were offered one such 60-day SEP after losing Med-QUEST coverage ${ }^{51}$ but it is unclear how many of them were enrolled during this period.

In contrast, Med-QUEST has no open enrolment period. Hence, prior to 2015, if a COFA resident was to fall seriously ill without being previously enrolled in coverage, the resident could be enrolled in coverage at the point of contact with the hospital. After 2015, if they were unenrolled at the time of illness, they faced catastrophic health expenditures.

While the consensus among health policy-makers is that open enrolment windows do limit adverse selection in private insurance markets, there is some evidence to the contrary. For example, in Massachusetts, waivers to open enrolment are generous; low-income individuals with income less than $300 \%$ of the federal poverty level can enrol at any time during the year. ${ }^{52}$ Despite this opportunity for adverse selection, the state has among the lowest-cost marketplace premiums in the nation. ${ }^{53}$ This might be explained by healthy procrastinators enrolling late and decreasing average risk, ${ }^{54}$ or an effective individual mandate which motivates all individuals to enrol to avoid paying fines. Despite this evidence, open enrolment remains the norm.

This highlights an important point. Open enrolment periods are likely to remain a fixture of private insurance markets because of an entrenched belief that they ensure the viability of private insurance plans. However, work has suggested that this also poses as a serious barrier to care for the most vulnerable. Consequently, relying on public insurance such as Medicaid, which permits enrolment 
at any time, may be preferable to private marketplaces when covering the poorest in the USA.

\section{CONCLUSION}

Understanding and addressing the obstacles that the most vulnerable face when attempting to access healthcare is critical towards any efforts to achieving universal coverage. This is especially the case in the USA, which cannot rely on mandates to achieve universal coverage as is done in other countries due to constitutional constraints. Researchers should further investigate the respective roles that better communication, lower bureaucratic burdens and cost sharing, and year-round open enrolment periods play in facilitating access to healthcare, improving patient outcomes and determining healthcare costs. Policy-makers should implement these recommendations while making efforts to maintain the viability of public and private health insurance markets.

While it is true that COFA migrants face unique barriers to accessing affordable health coverage, their experience can inform health policy for other vulnerable populations in the USA, particularly those in the Medicaid gap. The insurance gap that COFA residents of Hawaii fell into after 2015, and its devastating impact on healthcare use and outcomes, holds up a mirror to other states' decisions not to expand Medicaid as was originally intended by the ACA. This is a political decision to keep affordable healthcare out of reach for millions of Americans.

In the case of COFA migrants, there is some good news. Federal funding was reinstated to cover healthcare for COFA migrants in late $2020 .^{22}$ These changes must now be communicated to the population. However, it is unclear if, or how quickly, healthcare utilisation will increase, and whether there will be a meaningful recovery in health outcomes. Moreover, undoing the harms of racism and rebuilding trust with this vulnerable population will require commitment and effort from all sectors of society.

Twitter Joshua S Ng Kamstra @joshngkamstra

Contributors JSNK, TM and TH conceived the study. JSNK drafted the manuscript. All authors were involved with data interpretation and critical revisions of the paper and approve of the final version.

Funding The authors have not declared a specific grant for this research from any funding agency in the public, commercial or not-for-profit sectors.

Competing interests None declared.

Patient consent for publication Not applicable.

Provenance and peer review Not commissioned; externally peer reviewed.

Data availability statement All data relevant to the study are included in the article.

Open access This is an open access article distributed in accordance with the Creative Commons Attribution Non Commercial (CC BY-NC 4.0) license, which permits others to distribute, remix, adapt, build upon this work non-commercially, and license their derivative works on different terms, provided the original work is properly cited, appropriate credit is given, any changes made indicated, and the use is non-commercial. See: http://creativecommons.org/licenses/by-nc/4.0/.

\section{REFERENCES}

1 Wagstaff A, Flores G, Hsu J, et al. Progress on catastrophic health spending in 133 countries: a retrospective observational study. Lancet Glob Health 2018;6:e169-79.

2 Qin VM, Hone T, Millett C, et al. The impact of user charges on health outcomes in low-income and middle-income countries: a systematic review. BMJ Glob Health 2018;3:e001087.

3 Scott JW, Havens JM, Wolf LL, et al. Insurance status is associated with complex presentation among emergency general surgery patients. Surgery 2017;161:320-8.

4 Liu C, Chhabra KR, Scott JW. Catastrophic health expenditures across insurance types and incomes before and after the patient protection and Affordable care act. JAMA Netw Open 2020;3:e2017696.

5 Foiles Sifuentes AM, Robledo Cornejo M, Li NC, et al. The role of limited English proficiency and access to health insurance and health care in the Affordable care act era. Health Equity 2020;4:509-17.

6 McElfish PA, Hallgren E, Yamada S. Effect of US health policies on health care access for Marshallese migrants. Am J Public Health 2015;105:637-43.

7 Blumenthal D, Abrams M, Nuzum R. The affordable care act at 5 years. N Engl J Med 2015;372:2451-8.

8 Rosenbaum S. The patient protection and Affordable care act: implications for public health policy and practice. Public Health Rep 2011;126:130-5.

9 Blumenthal D, Collins SR, Fowler EJ. The affordable care act at 10 years - its coverage and access provisions. $N$ Engl $J$ Med 2020;382:963-9.

10 Halliday TJ, Akee RQ. The impact of Medicaid on medical utilization in a vulnerable population: evidence from COFA migrants. Health Econ 2020;29:1231-50.

11 Molina T, Sentell T, Akee RQ, et al. The mortality effects of reduced Medicaid coverage among international migrants in Hawaii: 20122018. Am J Public Health 2020;110:1205-7.

12 United Nations General Assembly. Resolution S/318, Trusteeship of strategic areas, 1947.

13 Guyer RL. Radioactivity and rights: clashes at Bikini Atoll. Am J Public Health 2001;91:1371-6.

14 Riklon S, Alik W, Hixon A. The "compact impact" in Hawaii: focus on health care. Hawaii Med J 2010;69:7-12.

15 McElfish PA, Purvis RS, Riklon S, et al. Compact of free association migrants and health insurance policies: barriers and solutions to improve health equity. Inquiry 2019;56:46958019894784.

16 McElfish PA, Purvis RS, Maskarinec GG, et al. Interpretive policy analysis: Marshallese COFA migrants and the affordable care act. Int $J$ Equity Health 2016;15:91.

17 Government of Hawaii. Demographic, social, economic, and housing characteristics for selected race groups in Hawaii. Honolulu, $\mathrm{HI}$ : State of Hawaii: Department of Business EDaT, 2018.

18 Drinkall S, Leung J, Bruch C, et al. Migration with dignity: a case study on the Livelihood transition of Micronesians to Portland and Salem, Oregon. Journal of Disaster Research 2019;14:1267-76.

19 Ruggles S, Flood S, Goeken R. IPUMS USA: Version 10.0. In: Minneapolis MN, ed. IPUMS, 2020.

20 Ined.United States Census Bureau. 2018 estimates of compact of free association (COFA) migrants. Commerce UDoWashington, DC, 2019.

21 Abercrombie N, McManaman P. COFA Residents and Health Care Assistance in Hawaii. In: Honolulu HI, ed. Services DoH, 2014.

22 Diamond D. 'A shining moment': Congress agrees to restore Medicaid for Pacific Islanders. Politico. Arlington, VA: Axel Springer SE, 2020.

23 Inada MK, Braun KL, Mwarike P. Chuukese community experiences of racial discrimination and other barriers to healthcare: perspectives from community members and providers. Soc Med 2019;12:3-13.

24 Rogers B, Dunne E. Treatment of COFA residents intolerable. In: The honolulu advertiser. Honolulu, HI: Gannett Pacific Corporation, 2010: A6.

25 Yamada S. Discrimination in Hawai' $i$ and the Health of Micronesians and Marshallese. Hawaii Journal of Public Health 2011;3:55-7.

26 Hofschneider A. Micronesians in Hawaii still struggle to get health care. Honolulu civil beat. Honolulu, HI: Honolulu Civil Beat, Inc, 2019.

27 Shek D, Yamada S. Health care for Micronesians and constitutional rights. Hawaii Med J 2011;70:4-8.

28 Hagiwara MK, Yamada S, Tanaka W, et al. Litigation and Community Advocacy to Ensure Health Access for Micronesian Migrants in Hawai'i. J Health Care Poor Underserved 2015;26:137-45.

29 Pobutsky A, Krupitsky D, Yamada S. Micronesian migrant health issues in Hawaii: Part 2: an assessment of health, language and 
key social determinants of health. Californian Journal of Health Promotion 2009;7:32-55.

30 Liou W. Word to the mother(tongue): language access and Medicaid for Limited English Proficient migrants. IZA J Develop Migration 2018;8.

31 Appel J, Atkins B, Denton-Spalding C. Hawaii's COFA Islanders : improving health access and outcomes : a report for the Governor of Hawaii, David Ige. Woodrow Wilson School of Public \& International Affairs, Princeton University, 2017.

32 The Auditor of the State of Hawaii. Audit of the Hawai'i Health Connector. Honolulu, HI: Office of the Auditor, 2015.

33 Musumeci M, Kates J, Dawson L. The Trump Administration's Final Rule on Section 1557 Non-Discrimination Regulations Under the ACA and Current Status, 2020. Available: https://www.kff.org/racialequity-and-health-policy/issue-brief/the-trump-administrations-finalrule-on-section-1557-non-discrimination-regulations-under-the-acaand-current-status/ [Accessed 30 Jul 2021].

34 Rice T. The behavioral economics of health and health care. Annu Rev Public Health 2013;34:431-47.

35 Fox AM, Stazyk EC, Feng W. Administrative easing: rule reduction and Medicaid enrollment. Public Adm Rev 2020;80:104-17.

36 Moynihan D, Herd P, Harvey H. Psychological, and compliance costs in Citizen-State interactions. Journal of Public Administration Research and Theory 2014;25:43-69.

37 Dorn S. Marketplace enrollment procedures: early barriers to participation and options for Surmounting them. The Urban Institute, 2014.

38 Fryling LR, Mazanec P, Rodriguez RM. Barriers to homeless persons acquiring health insurance through the Affordable care act. $J$ Emerg Med 2015;49:755-62.

39 Guerrero EG, Legnick-Hall R, Andrews C. Underlying challenges of public health insurance enrollment and use among Latino adults: insights from the largest safety-net institution in Los Angeles. Public Health 2017;152:47-50.

40 Richardson JB, Wical W, Kottage N, et al. The challenges and strategies of Affordable care act Navigators and In-Person Assisters with Enrolling uninsured, Violently injured young black men into healthcare insurance coverage. Am J Mens Health 2021;15:15579883211005552.
41 Sommers BD, Maylone B, Nguyen $\mathrm{KH}$, et al. The impact of state policies on ACA applications and enrollment among low-income adults in Arkansas, Kentucky, and Texas. Health Aff 2015;34:1010-8.

42 Marton J, Yelowitz A, Talbert JC. Medicaid program choice, inertia and adverse selection. J Health Econ 2017;56:292-316.

43 Government of Hawaii. 2014 SLCSP calculator, 2014.

44 Li Z, Li M, Fink G, et al. User-fee-removal improves equity of children's health care utilization and reduces families' financial burden: evidence from Jamaica. J Glob Health 2017;7:010502.

45 Park YJ, Martin EG. Medicare Part D's effects on drug utilization and out-of-pocket costs: a systematic review. Health Serv Res 2017;52:1685-728.

46 Fox KM, Grandy S, Group SS, SHIELD Study Group. Out-of-pocket expenses and healthcare resource utilization among individuals with or at risk of diabetes mellitus. Curr Med Res Opin 2008;24:3323-9.

47 Johansson N, Jakobsson N, Svensson M. Effects of primary care cost-sharing among young adults: varying impact across income groups and gender. Eur J Health Econ 2019;20:1271-80.

48 Newhouse J. An ounce of prevention; 2020, National Bureau of Economic Research. NBER Working Paper No. 27553.

49 Swartz K, Graves JA. Shifting the open enrollment period for ACA marketplaces could increase enrollment and improve plan choices. Health Aff 2014;33:1286-93.

50 Department of Health and Human Services,, Centers for Medicare and Medicaid Services. Patient protection and Affordable care act; market stabilization. Woodlawn, MD, 2017

51 Office of Governor David Y Ige. Enrollment in healthcare.gov extended for eligible Hawaii residents. Honolulu, HI: Hawai'i Free Press, 2015

52 Government of Massachusetts. How to request an open enrollment waiver, 2021. Available: https://www.mass.gov/how-to/how-torequest-an-open-enrollment-waiver [Accessed 27 Jul 2021].

53 Kaiser Family Foundation. Average marketplace premiums by metal tier, 2018-2021, 2021. Available: https://www.kff.org/health-reform/ state-indicator/average-marketplace-premiums-by-metal-tier [Accessed July 30, 2021].

54 Shafer P, Dusetzina S, To LA. Looking ahead to 2018: will a shorter open enrollment period reduce adverse selection in exchange plans? [Health Affairs Blog: Following the ACA web site], 2018. Available: https://www.healthaffairs.org/do/ [Accessed 25 Jul 2021]. 